\title{
Bitter Almond Oil
}

National Cancer Institute

\section{Source}

National Cancer Institute. Bitter Almond Oil. NCI Thesaurus. Code C107272.

The oil extracted from the seed press-cake of Prunus amyg dalus var. amara. Bitter almond oil is used as a flavoring and sweetener. 